\title{
Requiem for the Night Shift: In Memory Of...
}

\author{
David J. Rhine, MD, FRCPC* ${ }^{\dagger}$
}

Req.ui·em

(rekwēəm)

-noun

-an act or token of remembrance. ${ }^{1}$

Requiem for the Night Shift: In Memory Of...

.35

$\cdot 1260$

$\cdot 25,200$

$.20 \%$

First and last...

I'm awake. Had my anchor sleep, but I'm still groggy and trying to be civil to the people around me, the ones that really care about me, my family. It's the first morning after my last night shift as a full-time emergency physician. I'm not retiring, just done with nights and slowing down. "No nights after age (blank)" is not a group policy where I work... it's my own choice, and thankfully supported by my current group. But doesn't it seem reasonable? What is the toll of a shift-work career and the night shift?

I was finding the night shift more difficult to adjust to and requiring a longer pre-shift sleep. I could handle fewer distractions beforehand and was very aware of a longer post-night-shift recovery period. The next day was not as much of a readjustment, but there seemed to be more of an effect two days after the night shift. I was more taciturn, more withdrawn, and isolated myself more from life events. I didn't really like myself postnights for a day or two, nor did the people around me from time to time. The youthful days of working all night and playing all day were so far gone as to be mythical. The adrenaline rush of the night shift wasn't happening any more, and there wasn't a good enough tradeoff to continue to work those midnight shifts.

Night shifts in the ED do have an upside. The night shift seems to feed the "raison d'être" of most emergency physicians. Over the years, I have come to regard emergency physicians collectively as individuals who think we can make order out of chaos, while at the same time being dependent on the personal and private adrenalin rush that comes with a fast-paced, highly unpredictable work environment and the demands of complicated cases. For most ED docs, the night shift finds you alone, in charge, and making complex decisions that really matter. Administration is tucked away in their warm beds and not looking over your shoulder. The consulting services are happy to have you "hold the fort" until dawn, then more willing to move in and deal with the accrued "problems." The successes of the night shift can build you up; however, the mistakes and problems can drag you down. The cases vary, from mundane to rare and exciting. Last night in the last hour of my last night shift, I had a partial upper airway obstruction and an ST-elevation MI arrive back-to-back. The 0500 hour nadir of my alertness and responsiveness shattered by the demands of these sick patients-my adrenalin rush.

Of course, there is always what I call "the breakfast club," the early arrivers who have minor or long-term problems and present at 0600 hours to get a "jump" on the day. These patients have no idea what type of staff they are facing at the end of the night-cognitive capabilities and caffeine levels are zero and are commensurate with compassion levels, lab and $\mathrm{x}$-ray are busy elsewhere, staff are all at their mental and physical low points. I've been known to refer to the last hour of the shift as the "CPR hour"- if you don't need CPR, you can wait, and if you do need CPR, we'll see you, but since CPR doesn't work, the visit will be short. Do you really want to deal with this type of department?

The night shift ends with patient transfers and morning communications to admitting services. This is the moment in the shift when you feel the

1. Google Online Dictionary definition.

From the *University of British Columbia Okanagan, Faculty of Medicine, Kelowna, BC; and tDepartment of Emergency Medicine, Kelowna General Hospital, Kelowna, BC.

Correspondence to: David J. Rhine, 4968 Lakeshore Rd., Kelowna, BC, V1W 4H9; Email: djrhine1@shaw.ca

(C) Canadian Association of Emergency Physicians

CJEM 2016;18(4):319-320

DOI 10.1017/cem.2015.19 
accomplishment of creating order from the chaos, relating the night's interaction with our patients, your assessments and decisions based more often on clinical grounds than technological grounds. However, there can be occasional reluctance on the part of the admitting service to accept your night shift patients. The veteran ER doc handles this with the night shift trump card to the reluctant consultant in the morning: "The next time I'll call you at 0230 hours to discuss the case." This is usually a quick attitude-adjuster, and like any behavior modification tool, works well when used judiciously. My medical staff colleagues are almost always supportive and rarely act this way, so like cricothyrotomy, this remains a tool to remember but rarely to be used.

Will I miss nights? Yes, to some degree. There's more of an opportunity at night to get to know your staff, to engage with patients and family, and to see, immediately, that you can favorably affect someone's life. On the flip side, you also are more involved in the sorrow and despair of some cases, but this also gives more meaning to what we do. There's a satisfaction to knowing you have practiced clinical medicine efficiently and competently, and that you can have the department under control after a chaotic night. On the financial side, night shifts are more rewarding, and for a while I thought I couldn't give that up. For me now the tradeoff is not worth it and the "youngsters" in the group can reap the financial benefits and suffer the physical and mental toll of the ED night shift. Now that my night servitude is over, where will my adrenalin surge come from and what will satisfy my need to create order?
What is the toll? Here is my personal ED night shift balance sheet:

-35:

35 years as a full-time ER doc... (first ever FRCPC class, Royal College ER Specialist Certificate \#39)

-1260:

1260 Night shifts... (3.5 years of my life on-duty at night in the ER)

-25,200:

25,200 patients seen on night shift alone... (some bappy and some not, some regrets but mostly satisfied customers)

.20\%:

$20 \%$, the reduction effect that working nights has on your life span... (I'm in my early sixties now... Does that mean I'll only live to be 64 because of the night work that I did?)

-First and last:

First and last... (The first night shift was so long ago that I cannot remember it, and yet it hardly seems like any time has passed. My last night shift is done and I'll always try to remember it.)

No regrets. Whatever the price, it was worth it. I am an Emergency Physician, a chaos sorter, and a selfadmitted adrenalin junkie. The ED night shift will always be part of who I am.

Competing Interests: None to declare.

Keywords: Night shift, emergency physician, career in ER 